\title{
Multi-Criteria Decision Analysis of Heuristically Designed Light-Duty Vehicles Today and in 2035
}

\author{
Erik Wilhelm and Alexander Wokaun \\ Paul Scherrer Institut
}

Copyright (C) 2011 SAE International doi: $\underline{10.4271 / 2011-01-0727}$

\begin{abstract}
Evaluating options for reducing the environmental impact of light duty vehicles is complicated by the number of technologies being actively researched. In this work, various alternative transportation fuels such as ethanol, biodiesel, hydrogen, and electricity as well as advanced materials and drive-train concepts are analyzed for their environmental benefits compared to conventional diesel and gasoline vehicles. To objectively evaluate the impact of technology and fuel options on various stakeholder criteria under uncertainty (e.g. fuel and technology costs), it is necessary to consider how the technology may be applied to a broad set of vehicle designs. The heuristic vehicle design method uses rules from first principles and engineering practice to ensure vehicles in the design set (virtual fleet) are composed of self-consistent technology options. The resulting cost, performance, environmental, safety, and utility criteria are used as indicators for multi-criteria decision analysis (MCDA) based on responses from two general and one expert surveys on individual preferences for the various indicators. A sensitivity analysis on how stakeholder preference influences the optimal technology chosen by the MCDA algorithm is also performed to highlight the advantage of this approach in handling uncertainty by finding robust alternatives. The conclusions provide insight into the acceptance of present and future vehicle fuel and powertrain options for light duty transportation, and examine the underlying stakeholder preferences which need to be reconciled in order to reduce the environmental burden of personal transportation, with emphasis on finding technology that is robust across many stakeholder preference weightings.
\end{abstract}

\section{INTRODUCTION}

There are a multitude of technology options being researched and developed to reduce the environmental impact and cost of personal transportation while increasing performance, safety and utility. It is impossible to select one technology that meets the requirements of all stakeholders, necessitating analytical tools for identifying optimal solutions given varying goals. Multi-criteria decision analysis (MCDA) describes a class of methods for matching a stakeholder preference profile to a set of technologies that are described by criteria indicators. The challenge facing regulators in their attempts to reduce greenhouse gas emissions from transportation while increasing the security of transportation fuel supply is clearly shown in Figure 1. Consumer demand for more powerful, heavier cars has resulted in a low emphasis on reducing fuel consumption in Europe, and almost no emphasis on reducing fuel consumption in North America [1]. The only good news from an environmental perspective to be found in Figure 1 is that, for the past few years, sales of very low emissions vehicles have been growing exponentially in Europe (although the growth is still modest in absolute terms). These trends in consumer preference for vehicle criteria highlight that despite the growing political and media attention to transportation issues, only incremental progress has been made towards reducing fleet average energy consumption. This is in part due to the uncertainty and lack of information about technology that can satisfy consumer preferences with reduced environmental impact.

To find transportation technologies that are robust to uncertainties in cost and emissions assumptions, heuristically designed vehicles are modeled and simulated to characterize how different technology choices impact the input criteria listed in Table 1. The simulation results are used as indicator values for a multi-criteria decision analysis. Using this method, the global optimum vehicle for a given stakeholder may not be identified (although in many cases it is), but rather the 'acceptance plateau' of robust technologies which are all match or exceed stakeholder criteria preferences under various input assumptions can be found. The results form the basis for a decision making tool which can be applied by various stakeholders to aid good decisions. 


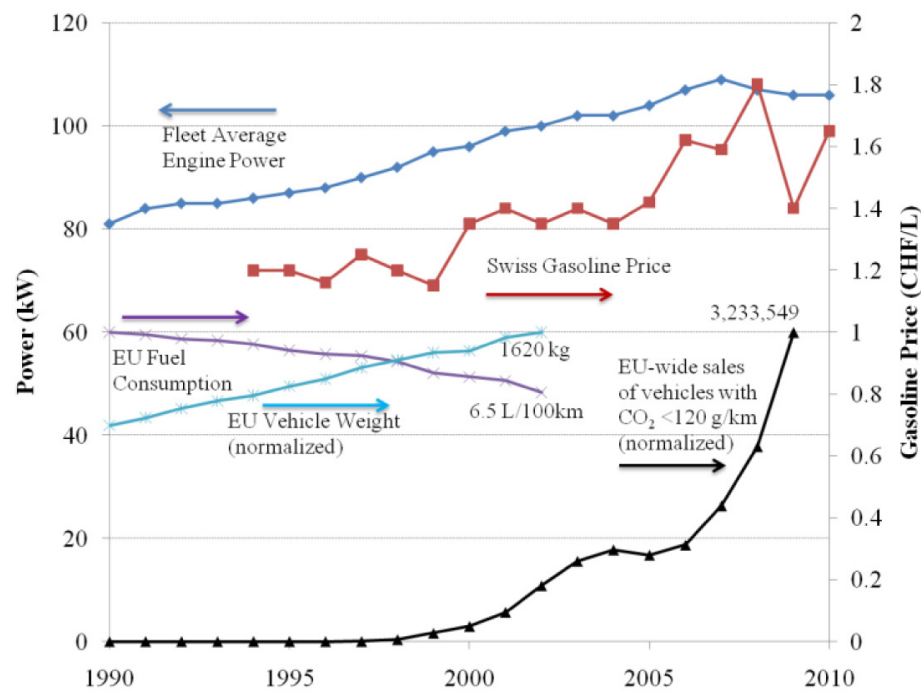

Figure 1. Historical European fleet characteristics. The trend towards lower fuel consumption could be accelerated if increases in vehicle mass and performance would be curbed [2], [3]

Table 1. Stakeholder criteria considered in this analysis

\begin{tabular}{|l|l|l|}
\hline Category & Criteria & Units \\
\hline Cost & Purchase & $\$$ \\
\hline & Total Cost of Ownership & $\$$ \\
\hline Performance & Acceleration 0-100 kph & $\mathrm{s}$ \\
\hline & Top Speed & $\mathrm{kph}$ \\
\hline Utility & Driving Range & $\mathrm{km}$ \\
\hline & Passenger Capacity & $\mathrm{m}^{3}$ \\
\hline Environment & $\mathrm{CO}_{2}$ emissions & $\mathrm{g} / \mathrm{km}$ \\
\hline & $\mathrm{NO}_{\mathrm{x}}$ emissions & $\mathrm{g} / \mathrm{km}$ \\
\hline
\end{tabular}

\section{HEURISTIC VEHICLE DESIGN}

Heuristic vehicle design methods use rules drawn from first principles (e.g. power-to-weight relationships) as well as from design and engineering practice (e.g. matching powertrain to vehicle class). In this work, the rules (heuristics) are applied to the technology options listed in Appendix A to generate a 'virtual fleet' for trade-off and multi-criteria decision analysis. The heuristic design algorithm (HDA) uses a combinatorial approach to generate a design set from exogenous technology options (e.g. hybridization architecture). Endogenous technology options (e.g. size of engine) are then added to the design set based on exogenous characteristics. Finally, through recursive analysis on the design set, dependent endogenous options are added (e.g. battery charge). After simulation, designs which prove to be physically infeasible for various reasons (e.g. underpowered), are removed from the set. The strength of this approach is that it formalizes and makes explicit the method of choosing technologies of interest, as well as providing an input which is very suited for MCDA. The weakness of the approach is the necessarily reduced fidelity of the powertrain models meaning that care must be taken to validate results, particularly concerning life-cycle emissions for various vehicles. A typical result contrasting the heuristic with the case study approach is shown in Figure 2.
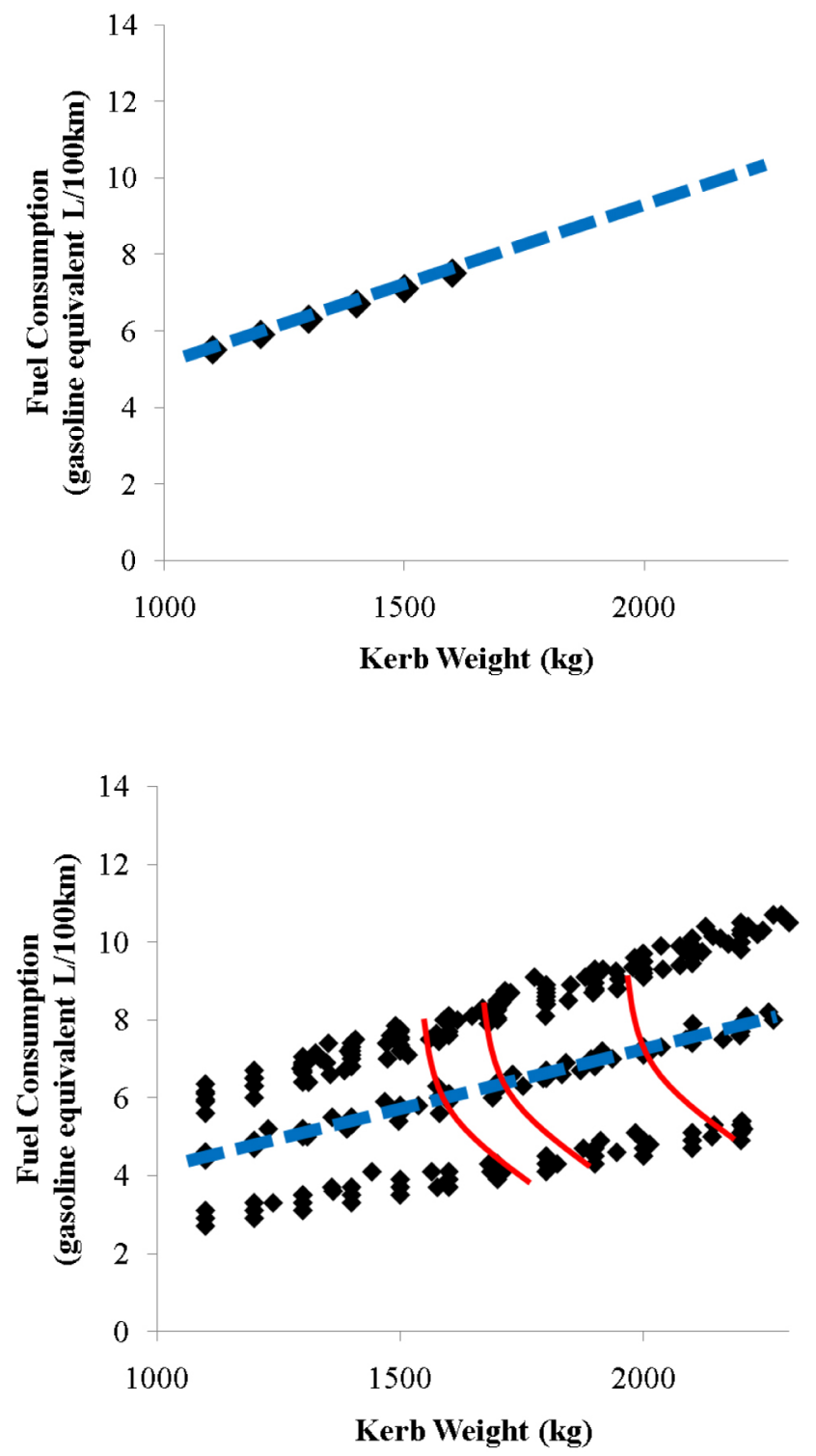

Figure 2. The top-down case study approach to vehicle technology assessment (top panel, single vehicle type) involves significant extrapolation but more detailed models.

The bottom-up heuristic vehicle design approach (six different powertrain types) allows interpolation of characteristics but sacrifices model detail. The relationship between powertrain hybridization and weight can be identified using both methods (blue dashed line) but the heuristic approach allows additional relationships such as battery size effects to be identified (red solid lines) 
A further advantage of the heuristic approach is its ability to identify Pareto-optimal technology families using a criteria trade-off plot for the 'virtual fleet' of vehicles.

\section{DETERMINISTIC DYNAMIC PROGRAMMING}

In order to objectively compare different hybrid vehicle architectures while varying technology options such as motor size, battery size, transmission characteristics, engine size, etc. it is necessary to ensure that each hybrid vehicle powertrain is controlled in an optimal way over a given driving cycle. If control optimization is not performed, there is a risk that nominal changes in technology options (e.g. increasing battery charge by a few Ah) will have a dramatic impact on criteria results. The mechanism often at the root of this undesirable occurrence in vehicle simulation is that control strategy thresholds are reached slightly earlier during a driving cycle and hence the engine is engaged for more time to recharge the larger battery, than it did when the battery was slightly smaller, for example. There are many methods in common practice to perform hybrid control optimization. For this work, the deterministic dynamic programming (DDP) method was selected [4], []].

To perform dynamic programming, a state space is created for a mission (i.e. driving cycle, discretized with index $k$ ) and a cost function $J$ is defined (i.e. fuel consumption based on powertrain characteristics). The final cost-to-go is defined for the cycle according to Equation 1. The algorithm then works backwards through the driving cycle time, at each step attempting to find the optimal control rule $u_{k}$ that satisfies Equation 2. In the case of deterministic dynamic programming for hybrid vehicles, the state variable $x_{k}$ is selected as the battery state of charge. The function $g$ is the incremental cost for a step, and $f$ represents the cumulative costs resulting from later steps which have already been optimized to this point.

$$
\begin{gathered}
J_{N}\left(x_{N}\right)=g_{N}\left(x_{N}\right) \\
J_{k}\left(x_{k}\right)=\min _{u_{k} \in U_{k}\left(x_{k}\right)}\left(g_{k}\left(x_{k}, u_{k}\right)+J_{k+1}\left(f_{k}\left(x_{k}, u_{k}\right)\right)\right)
\end{gathered}
$$

The optimal control map that results from DDP over the new European driving cycle (NEDC) is shown in Figure 3. The shading of each pixel in grey scale represents the optimal control signal to go to the next step based on the state that the vehicle is in at the current step. The red lines represent various starting states of charge (SOC) for the vehicle, and the optimal SOC progression. The blue lines show how state of charge can vary drastically for a non-optimized control strategy with different powertrain technologies, highlighting the necessity for optimizing control to perform broad powertrain technology analysis.

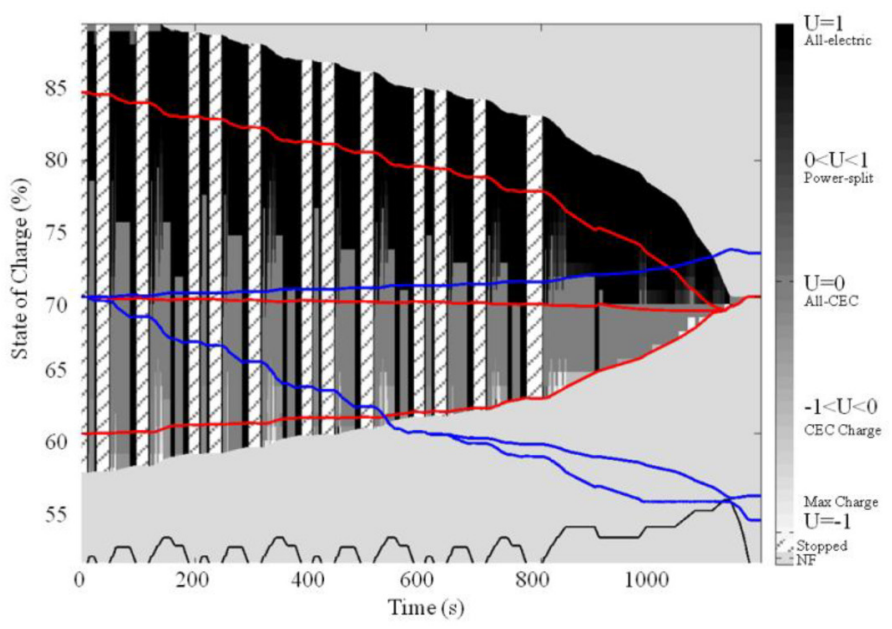

Figure 3. Optimal control applied to a parallel hybrid with various initial states of charge showing how heuristic control rules (blue) cannot guarantee final charge whereas optimal control rules (red) can, thereby reducing variability in technology analysis. The colour map represents the optimal control rule, with $U=1$ (all-electric) in black, and $U=-1$ (full power chemical) in white.

In this work, charge neutrality is assumed for all hybrid vehicles so the initial SOC is equal to the final SOC. For more detail on the methods used here, please refer to [ 6$]$.

\section{RESULTS AND DISCUSSION}

The heuristically vehicle design set (HDVS) consisting of over 2000 designs was modeled and simulated according to the assumptions listed in Appendix B. This list is not exhaustive, and a more detailed discussion of the main assumptions can be found in [7]. To provide insight into how several tradeoffs between criteria important to stakeholders are represented by the HVDS, the main vehicle characteristics are listed in Appendix C. For example, the trade-off between low environmental impact versus the cost of advanced powertrain technology required to reduce emissions, or the much debated trade-off between range and environment (particularly important for all-electric and fuel cell options) can be identified in the table using the color scheme to identify the best and worst designs for a given criteria. The results presented in this section are divided into sensitivity analysis and survey multicriteria decision analysis. In this way, the scenarios are properly introduced and the sensitivity of the results to input assumptions can be gauged before they are used to evaluate the survey multi-criteria decision analysis. 


\section{SENSITIVITY ANALYSIS}

The sensitivity of the top vehicle design selected using multicriteria decision analysis for the eight criteria listed in Table 1 is investigated by setting the preference for six criteria to a nominal value of 0.2 , and then varying the remaining two criteria preference values in increments of 0.2 . The result for greenhouse gas (GHG) and performance preference sensitivity is shown in Figure 4 where twenty-five top-ranked vehicle designs for selected for various levels of GHG and Performance preference are represented in terms of their $\mathrm{CO}_{2}$ emissions. The ability to classify designs according to engine displacement is clearly shown, i.e. for high performance preference larger displacement engines are chosen. Bio-diesel parallel hybrids are exclusively selected because of their low total GHG emissions and low fuel cost compared to other fuels, demonstrating their robustness in the 2035 renewable scenario.

These results agree with expectations, but the sensitivity analysis is not complete without an investigation of the sensitivity of the results to indicator performance. Besides the vehicle criteria performance listed in Appendix $\mathrm{C}$ which are validated separately [ $[\underline{8}$, the sensitivity of the MCDA results to cost and emissions intensity of primary energy was investigated.

The procedure that was followed for performing sensitivity analysis on the input set is as follows:

1. Select preference level limits (i.e. high $=0.8$, low $=0.2$ ),

2. Generate stakeholder preferences by permuting every combination of two preference levels for eight criteria (i.e. number of stakeholders $=2^{8}$ ),
3. Run MCDA for all 256 stakeholder preference combinations over the 2232 vehicle designs in the complete set,

4. Filter MCDA results to identify robust technologies (classes or subsets of vehicles sharing a particular attribute) by counting the appearance of a technology class in the top ranking of the design set

The twelve input assumption scenarios analyzed are listed in Table 2. More detail on the baseline assumptions can be found in Appendix B.

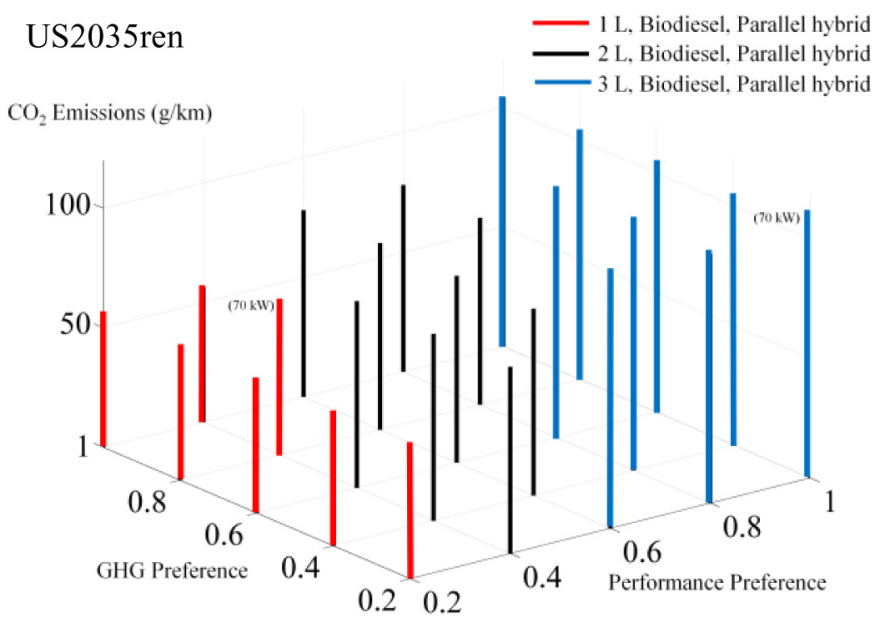

Figure 4. Top ranked designs for various stakeholder preferences in the US 2035 renewable scenario. Bio-diesel (from soya) parallel hybrid options are selected exclusively, with higher displacements being preferred as performance preference increases.

Table 2. Scenarios for fuel and powertrain technology price. US renewable scenarios assume only PV electricity for hydrogen production and battery charging, and therefore represent extreme sensitivity bounds for analysis of technology adoption.

\begin{tabular}{|c|c|c|}
\hline & Scenario Name & Scenario Assumptions \\
\hline 1 & 2010 baseline & US $2010 \mathrm{v}$, high $=0.8$, low $=0.2 *$ \\
\hline 2 & 2035 renewable & US 2035ren(PV), 0.8 high, 0.2 low \\
\hline 3 & 2010 baseline $8 \mathrm{x}$ fossil & US 2010v $8 \times$ fossil price, $2 \mathrm{x} \mathrm{H}_{2}$ price, 0.8 high, 0.2 low \\
\hline 4 & expensive fossil + battery & US $2010 \mathrm{v} 8 \times$ fossil price, $2 \mathrm{x} \mathrm{H}_{2}$ price, exp. batt, $50 \%$ cheaper $\mathrm{FC}, 0.8$ high, 0.2 low \\
\hline 5 & cheap FC & US 2010v 8 x fossil price, $2 \mathrm{x} \mathrm{H}_{2}$ price, exp. batt, $50 \%$ cheaper FC, 1 high, 0.1 low \\
\hline 6 & renewable cheap FC & US 2035 ren $8 \times$ fossil price, $2 \mathrm{x} \mathrm{H}_{2}$ price, $50 \%$ cheaper $\mathrm{FC}$, exp batt. 1 high, 0.1 low \\
\hline 7 & renewable cheap FC + battery & US 2035 ren $8 \times$ fossil price, $2 \mathrm{x} \mathrm{H}_{2}$ price, $50 \%$ cheaper $\mathrm{FC}, 1$ high, 0.1 low \\
\hline 8 & improved FC acceleration & US 2035ren $8 \times$ fossil price, $2 \mathrm{x} \mathrm{H}_{2}$ price, $50 \%$ cheaper $\mathrm{FC}, 1$ high, 0.1 low, low fc acceleration time \\
\hline 9 & improved EV acceleration & US 2035 ren $8 \times$ fossil price, $2 \mathrm{x} \mathrm{H}_{2}$ price, $50 \%$ cheaper $\mathrm{FC}, 1$ high, 0.1 low, low fc/batt. acceleration \\
\hline 10 & very cheap FC & US 2035ren $8 \times$ fossil price, $2 \mathrm{x} \mathrm{H}_{2}$ price, $\$ 30 / \mathrm{kW} \mathrm{FC}^{* *}, 1$ high, 0.1 low, low fc/batt. acceleration \\
\hline 11 & extremely cheap FC & US 2035ren $8 \times$ fossil price, $2 \mathrm{x} \mathrm{H}_{2}$ price, $\$ 15 / \mathrm{kW}^{* *}, 1$ high, 0.1 low, low fc/batt. acceleration \\
\hline 12 & very cheap battery & US $2035 \mathrm{ren} 8 \mathrm{x}$ fossil price, $2 \mathrm{x} \mathrm{H}_{2}$ price, $\$ 15 / \mathrm{kW} * *, 50 \%$ batt cost, 1 high, 0.1 low, low fc/batt. accel. \\
\hline
\end{tabular}

* high preference value set to 0.8 , low preference value set to 0.2

** Extreme (optimistic) values to test sensitivity bounds 
The top $1 \%$ of the MCDA results was selected, and the number of times a technology option appeared in this sub-set of the total MCDA ranking was counted. For fuel technologies, shown in Figure 5 , the move to renewable primary energy was the driving force behind the adoption of hydrogen fuel. Increasing fossil fuel price significantly and reducing the price of fuel cell technology alone was not sufficient to increase the number of times hydrogen fuel appeared in the top MCDA rankings. Even when fuel cell price was reduced significantly, hydrogen still only appeared in the top $1 \%$ as a combustion fuel in Otto engines. Interestingly, battery electric vehicles never appeared in the top $1 \%$ of selected designs, likely because of the low range that they offer relative to the other technology options.

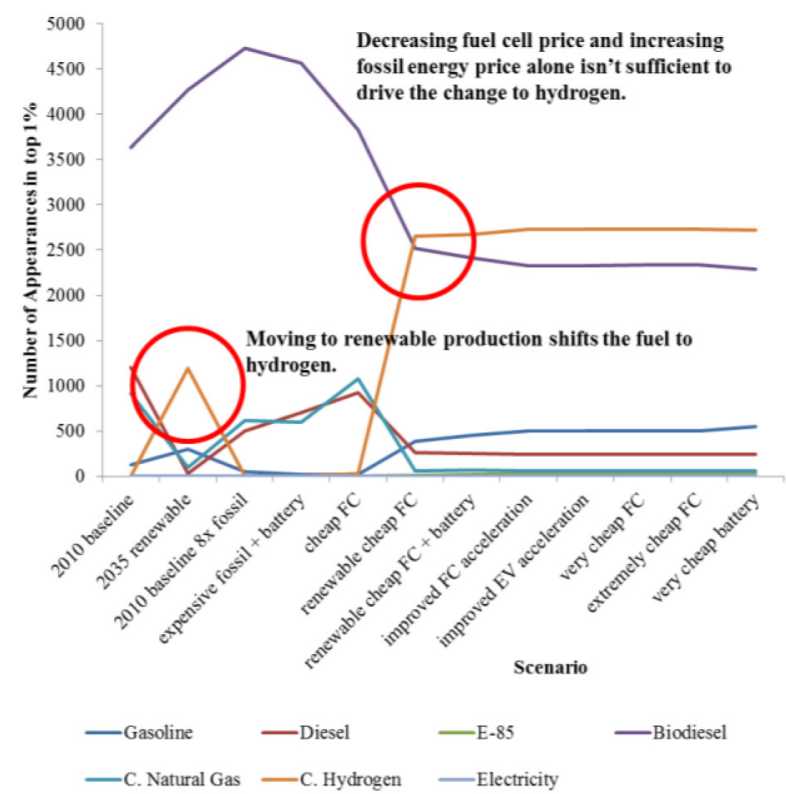

Figure 5. The robustness of fuel technology classes for combinatory stakeholder preferences. If renewable primary energy is used, hydrogen fuel is preferred. Increasing fossil fuel price while decreasing fuel cell price cannot drive this technology change alone.

Examining hybridization options across the MCDA rankings, it is clear from Figure 6 that series hybrid architectures are strongly preferred, particularly when fossil fuel price is increased, due to their high efficiencies. Parallel hybrids win share at the expense of mild hybrids in the top $1 \%$ of the stakeholder rankings as parallel bio-diesel vehicles are chosen more often with renewable fuel and when more stringent emission standards are introduced. This trend will appear again when analyzing the robustness of technology for singlestakeholders, adding to the conclusion that series bio-diesel hybrids represent a robust technology combination for the US fuel price assumptions.

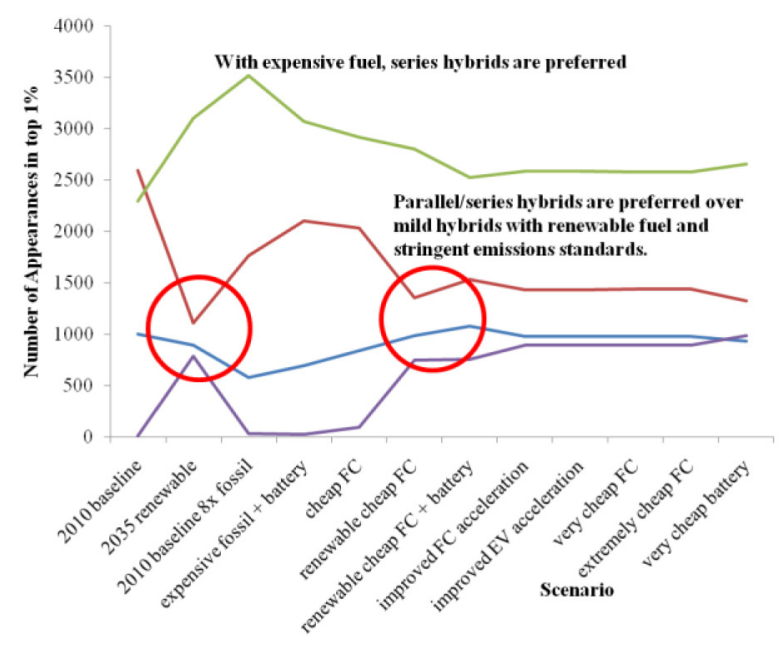

—Non-hybrid -Mild Hybrid - $\quad$ Series Hybrid —Parallel Hybrid

Figure 6. The robustness of hybrid technology for combinatory stakeholder preferences. As emissions limits get more stringent and the primary energy mix gets cleaner, parallel and series hybrids are more likely to be chosen.

Examining the number of times light weighting technologies are selected in the top $1 \%$ of the MCDA rankings for the general stakeholder set shown in Figure 7, it is observed that as fossil fuel prices become high, aluminum body technology is selected over high-strength steel despite its much higher cost. When more efficient powertrains are chosen based on lowemission primary energy, the advantage of aluminum over

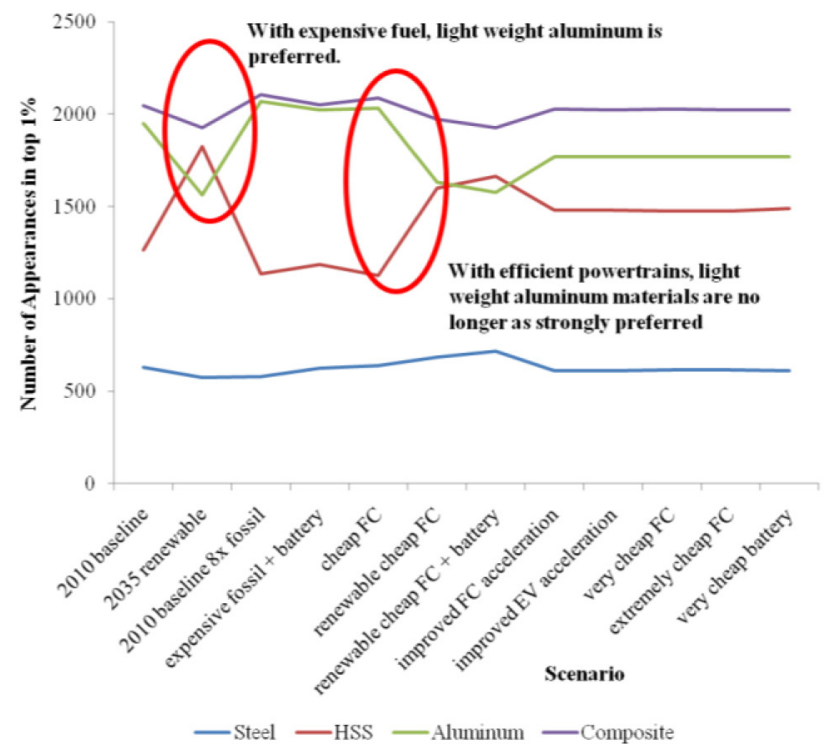

Figure 7. The robustness of light weighting technology for combinatory stakeholder preferences. As more efficient powertrains are selected as a result of low-carbon fuel availability, expensive aluminum technology is not as attractive an option. 
high-strength steel (HSS) is apparently diminished such that aluminum is no longer as dominant (although still preferred above the baseline steel body types). The trend in Figure 7 is also observed considering single-stakeholder preferences over the input set sensitivity.

\section{SURVEY RESULTS}

Three independent web surveys were performed using 2ask. com software in order to investigate the stated preferences of the general public. The response rate for all surveys was high, and averaged $40 \%$. An analysis of the results, however, showed that the demographic of the respondents is very similar $(40 \%$ of the respondents between the ages of 26-30, most rated their education and income as 'high'), and thus the decision was made to differentiate only between the aggregate of the first two general surveys (S1 and S2) and the expert survey (S3). The expert survey asked automotive R\&D managers and executives to estimate how they expect general stakeholders to respond to the questions they were asked in the first two surveys. Figure 8 hows how S1 was grouped into three categories based on frequency of driving, S2 was grouped by car ownership, and S3 represented only one stakeholder group (all expert respondents had remarkably similar preferences).

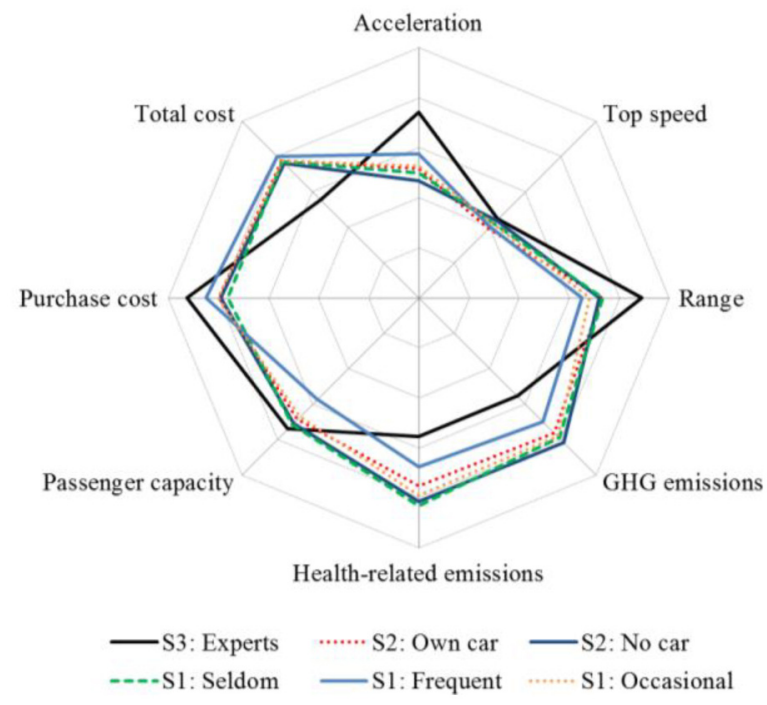

Figure 8. Stakeholder profiles (relative weights of indicated criteria) for three surveys on vehicle preferences. Note the lack of significant variation between the first two stakeholder general survey groups (S1 and S2) relative to the expert survey stakeholder group (S3).

For the following analysis, the $\mathrm{S} 1$ and $\mathrm{S} 2$ groups are aggregated and the average of these five groups will be referred to as the 'General' stakeholder. This averaging is performed for clarity, and is justified by the marginal difference between the survey respondent's stated preferences. The S3 expert group responses were aggregated, and will be referred to as the 'Expert' stakeholder. The survey respondents preference for total cost of ownership was calculated by calculated an un-weighted average of the responses for purchase cost, operating cost (including fuel), and maintenance cost.

\section{MULTI-CRITERIA ASSESSMENT RESULTS}

Series hybrids with bio-diesel fuel are selected most often across the present and future scenarios for both stakeholders. To provide an overview of the MCDA rankings for fuel and hybrid options, Figures 9 and $\underline{10}$ show the option (on the $y$-axis) and the rank of each design (x-axis) in the design set.
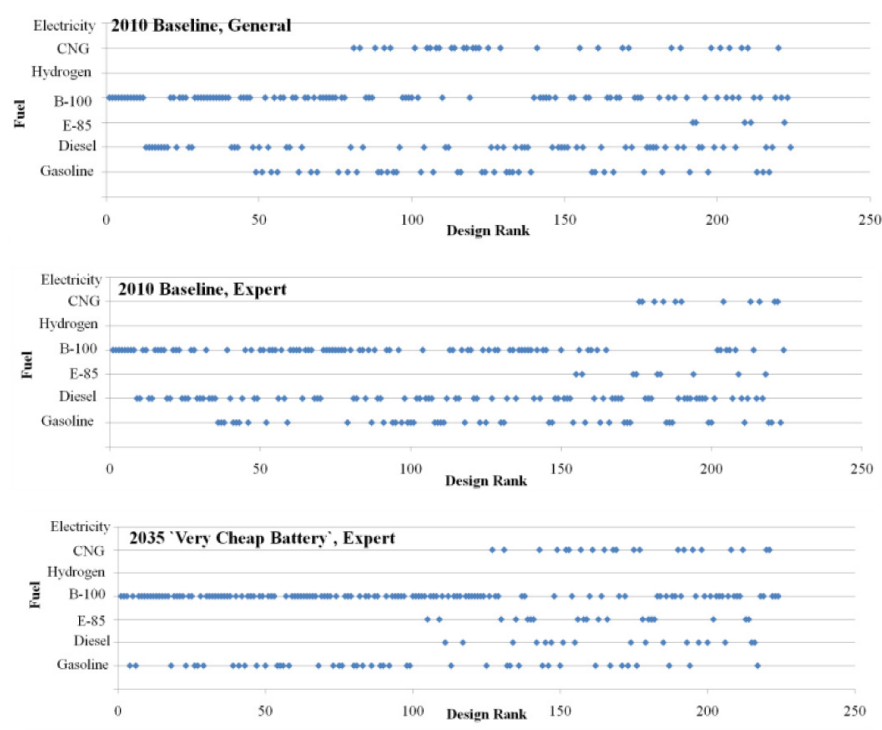

Figure 9. Ranking of fuel technology for general and expert stakeholders. Biodiesel occupies many of the top-ranked positions.

From Figure 9 it can be seen that bio-diesel and diesel fuelled vehicles occupy the first 50 positions of the 2010 baseline set for the 'General' stakeholder, whereas the 'Expert' selects some gasoline models in the top $50(2 \%)$. As the input scenario is changed to the most favorable case for alternatives (high fossil prices, cheap renewable fuel and powertrain technology) more gasoline parallel hybrids are selected by the 'Expert' as can be seen in Figure 10. Mild hybrids dominate in the current scenarios, while series hybrids occupy the top ranks in the 2035 scenarios.

This individual design rank analysis is complimented by examining the distribution of the designs by characteristic and powertrain for the top $25 \%$ of the rankings, as shown in Figures 11 and 12 . Passenger capacity has been omitted from this design because of how little this varies across the heuristic design set (although designs with large batteries are penalized for impinging in passenger volume). 

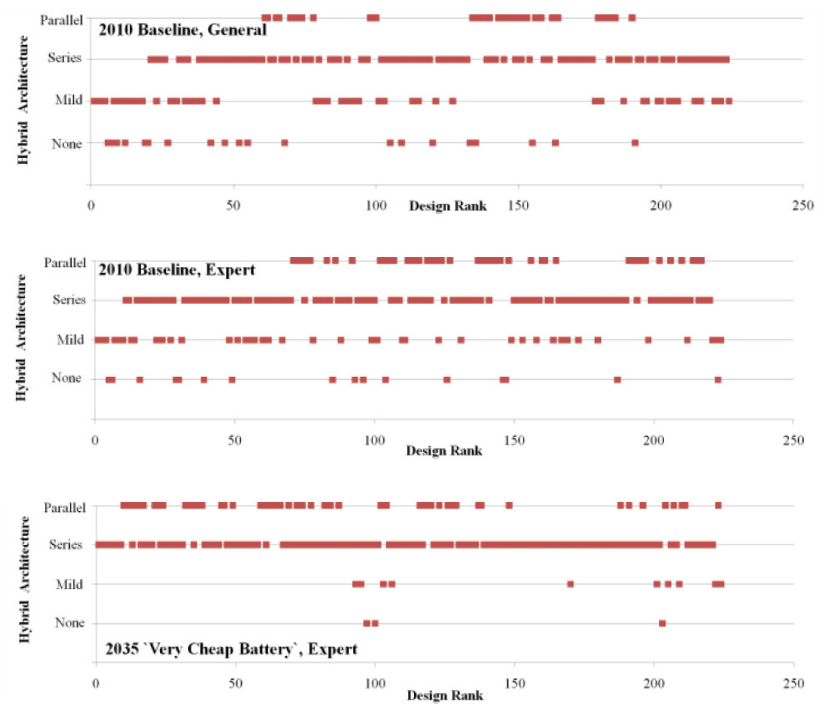

Figure 10. Ranking of hybrid technology for general and expert stakeholders. Series hybrids are strongly preferred under future conditions (bottom pane) whereas mild hybrids are more strongly preferred for present technology assumptions (top panes).

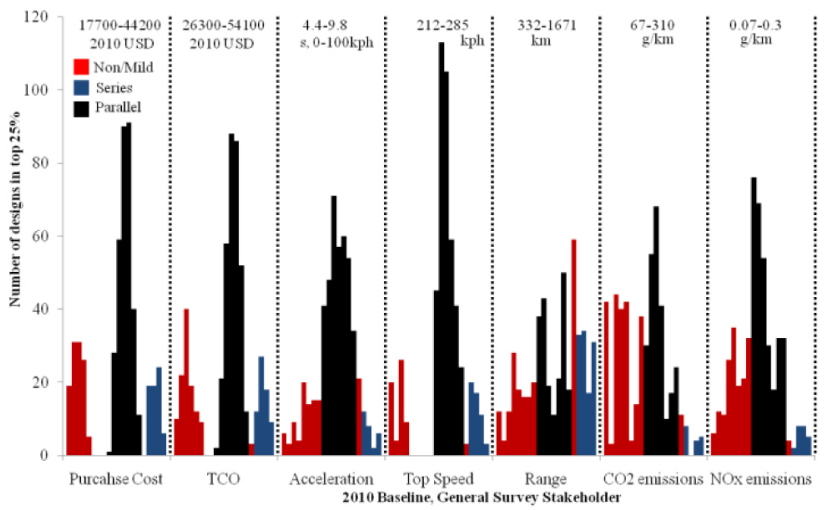

Figure 11. Design set distribution for the top $25 \%$ of ranked vehicle designs for the 2010 baseline 'General' stakeholder. The top five are mild bio-diesel hybrids.

For the top $25 \%$ of the ranked vehicle designs, it is apparent in comparing Figure 10 and 11 for the 2010 Baseline 'General' stakeholder that the preference is for the cheapest, fastest (in terms of acceleration) and lowest emissions vehicles. This all agrees with the way the stakeholder profile was generated, shown in Figure 8. When comparing this conclusion to what is shown in Figure 12, where the 'General' stakeholders' preferences are evaluated in 2035 for the 'Very Cheap Battery' scenario (which is also strongly favorable to all other alternatives), we see series hybrids playing a stronger role, exactly as is seen for the 'Expert' case in Figure 10. It is also interesting to note that the acceleration time deemed acceptable in the future set is almost a full second higher than that of the current set, suggesting that the high preference for low emissions in the 'General' stakeholder is playing a greater role.

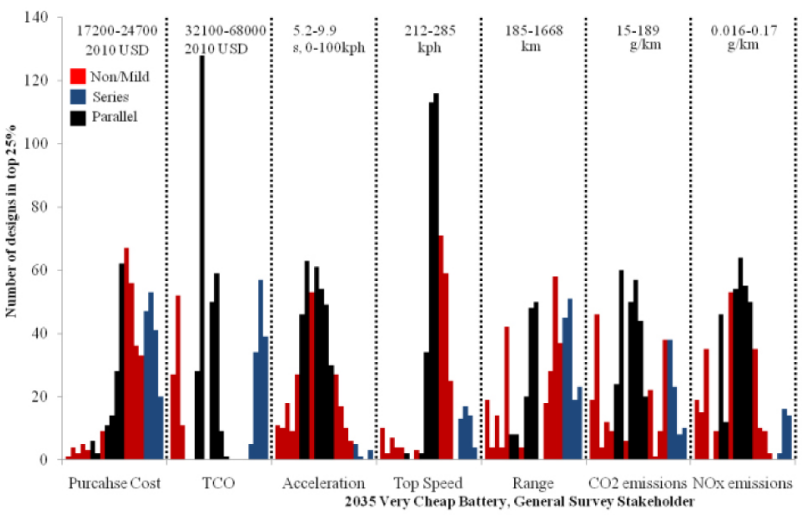

Figure 12. Design set distribution for the top 25\% of ranked vehicle designs for the 2035 'Very Cheap Battery' 'General' stakeholder. The top five are still bio-diesel series hybrids, but gasoline series hybrids are now entering the top ten.

A scenario sensitivity analysis for both stakeholders was performed, and many of the same trends seen in robustness analysis, such as preference for bio-diesel series hybrids, were also observed. Note that scenario 5 'Cheap FC' described in Table 2 was omitted from this sensitivity analysis because it was deemed unnecessary to evaluate the sensitivity of preference level limits a second time. From Figure 13 it is clear that series hybrids are still the preferred hybridization option, most often using bio-diesel fuel. In contrast to the many-stakeholder sensitivity analysis, parallel hybrids are chosen in the top $25 \%$ more than mild hybrids. The higher counting cut-off was an attempt to capture trends beyond the small one to two percent of top designs. The fact that we observe the same technology dominating in both cases suggests that it is a robust option.

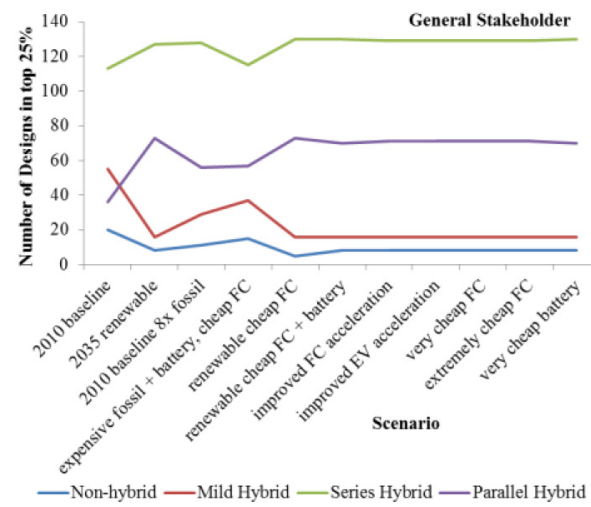

Figure 13. Top 25\% of MCDA ranked hybridization options for the 'General' stakeholder over various input assumption scenarios. The series hybrid share is dominant, followed by parallel hybrids. Non-and mild hybrids are not often in the top $25 \%$. 
The only example of fuel cell vehicles being selected in the design set is shown in Figure 14 for the 'General' stakeholder under renewable primary energy conditions where fuel cell vehicles are given a reasonable acceleration boost (assumed to come from over-utilizing the hybrid battery in short bursts). Interestingly, the appearance of fuel cells in the top $25 \%$ of ranked designs is not encouraged by the steep reduction in price for these powertrains, which is an artifact that will be the topic of further study.

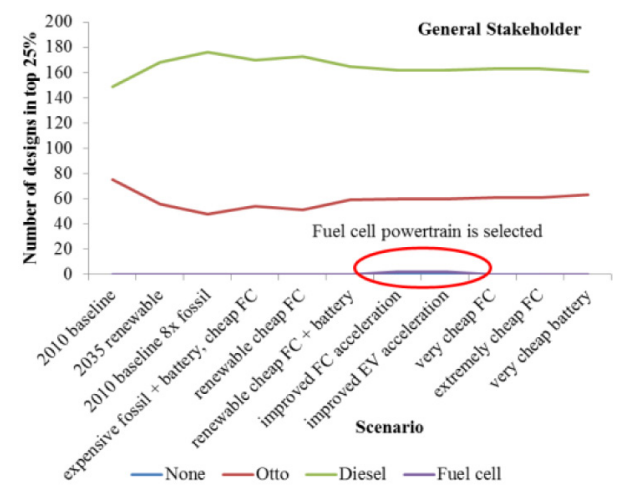

Figure 14. Top 25\% of MCDA ranked chemical energy converter options for the 'General' stakeholder over various input assumption scenarios. Fuel cells are chosen when acceleration is improved, but are not selected as batteries become cheaper.

Not shown in the figures in this section, but worth mentioning, is that lightweight materials (in particular carbon fiber body panels) are preferred by both stakeholders, over all scenarios, a trend also seen in the MCDA sensitivity study.

\section{SUMMARY/CONCLUSIONS}

The conclusions that can be drawn based on the results presented are that

1. Heuristic vehicle design and simulation with control optimization provides an ideal virtual fleet input for multicriteria decision analysis, and this approach is well suited to managing uncertainty in decision making,

2. Statistically significant clusters can be formed from the responses of 212 stakeholders, but for clarity the clusters can also to be grouped into a single stakeholder category,

3. General stakeholders prefer low emissions, low cost, and high utility, above performance (which contradicts observed sales patterns), while expert survey respondents shared significantly different ideas about what consumers prefer in vehicles,

4. Mild hybrids using bio-diesel fuel tend to satisfy the average 'General' stakeholder, whereas series and parallel bio-diesel vehicles tend to satisfy 'Expert' stakeholder preference weightings for 2010 input assumptions,
5. Bio-diesel tends to be a very robust option across many input assumptions driven by low fuel price and GHG emissions, and

6. Hydrogen fuel is selected for combustion engines when it is produced using low-carbon primary energy.

Please visit http://multicriteria-analysis.com/ for more detailed descriptions of these results and methods, as well as for the opportunity to evaluate your own personal vehicle preferences.

\section{REFERENCES}

1. Bandivadekar, Anup et al., "Reducing the Fuel Use and Greenhouse Gas Emissions of the U.S. Vehicle Fleet," 23-Apr-2007.

2. ACEA, New Passenger Car Registrations European Union + EFTA Countries. ACEA, 2007.

3. Zachariadis, T., "On the baseline evolution of automobile fuel economy in Europe," Energy Policy, vol. 34, no. 14, pp. 1773-1785, Sep. 2006.

4. Guzzella, L. and Sciarretta, A., Vehicle Propulsion Systems: Introduction to Modeling and Optimization, 2nd ed. Springer Verlag, Berlin, Germany, 2007.

5. Wokaun, A. and Wilhelm, E., Eds., "Technical Characterisation and Multi-Criteria Analysis of Light-Duty Vehicles," in Transition to Hydrogen: Pathways Toward Clean Transportation, Cambridge, UK: Cambridge University Press, 2011.

6. Sundström, O., Ambühl, D., and Guzzella, L., "On Implementation of Dynamic Programming for Optimal Control Problems with Final State Constraints," in Les Rencontres Scientifiques de l'IFP - Advances in Hybrid Powertrains, 2008.

7. Wilhelm, E. and Schenler, W., "Reducing the weight of electric, hybrid, and fuel cell vehicles using heuristic design," presented at the 2010 International Advanced Mobility Forum, Geneva, Switzerland, 2010.

8. Wilhelm, E. J. and Schenler, W. W., "Heuristic Design of Advanced Drives: Analysis of Trade-offs in Powertrain Electrification," World Electric Vehicle Journal, vol. 3, 2009.

\section{CONTACT INFORMATION}

Alexander Wokaun

Paul Scherrer Institut

Villigen PSI, CH-5232, Switzerland

+41(0)563105147

alexander.wokaun@psi.ch 


\section{ACKNOWLEDGMENTS}

This work has been supported by the Swiss Competence Center Energy and Mobility (CCEM-CH), and has been performed in collaboration with the MIT Sloan Automotive Laboratory and the industrial partners Ford and ENI under the framework of the Alliance for Global Sustainability. Special thanks to Dr. Warren Schenler for his support during this work. The partner CCEM project THELMA (thelma-emobility.net) focused on themes relating to electric mobility should also be acknowledged for providing useful inputs.

\section{DEFINITIONS/ABBREVIATIONS}

\section{DDP}

Deterministic dynamic programming

\section{GHG}

Greenhouse gas
HDA

Heuristic design algorithm

HVDS

Heuristic vehicle design set

MCDA

Multi-criteria decision analysis

SOC

State of charge 


\section{APPENDIX}

\section{Appendix A: Vehicle Technology Options}

\begin{tabular}{|l|l|c|l|}
\hline Option & Category & $\#$ & Technologies \\
\hline Classes & Exog. & 3 & Compact, Sedan, Truck \\
\hline Market & Exog. & 2 & Passenger, Sport \\
\hline Engine & Exog. & 4 & Otto, Diesel, Fuel cell, Electric motor \\
\hline Emission Control & Dep. End. & 2 & Selective catalytic reduction, Particulate filter (open/closed) \\
\hline Hybridization & Exog. & 4 & None, Mild, Plug-in series, Parallel \\
\hline Body Structures & Exog. & 4 & Steel, High-strength steel, Aluminum, Composite \\
\hline Fuel & Endog. & 7 & Gasoline, Diesel, E-85, B-100, CNG, Hydrogen, Electricity \\
\hline Primary Energy & Dep. End. & 4 & Fossil, Biomass, Renewable, Nuclear \\
\hline Displacement (L) & Endog. & 12 & $1.0,1.1,1.7,1.9,2.0,2.1,2.7,2.9,3.0,3.1,3.7,3.9$ \\
\hline Fuel Cell Power $(\mathrm{kW})$ & Endog. & 3 & $80,90,100$ \\
\hline Electric Path Power $(\mathrm{kW})$ & Endog. & 10 & $3,30,40,50,60,70,80,90,100,110$ \\
\hline Battery Chemistry & Endog. & 2 & NiMH, Li-ion \\
\hline $\begin{array}{l}\text { Charge /Average Energy } \\
\text { (Ah/kWh) }\end{array}$ & Dep. End. & 10 & $0.5 / 0.18,4.5 / 1.7,10 / 3.8,20 / 7.5,30 / 11.3,40 / 15,50 / 18.8,60 / 22.5$, \\
& & & $70 / 26.3,80 / 30$ \\
\hline & Total: & $155 \mathrm{e} 6$ & \\
\hline
\end{tabular}




\section{Appendix B: Selected Model Input Assumptions}

Note that the grid mix assumed for 2035 which consists exclusively of renewable primary energy is highly optimistic considering the current state of the US grid, and should hence be considered in this way.

\begin{tabular}{|c|c|c|c|c|}
\hline Selected Powertrain Cost & US $2010 \mathrm{v}$ & US 2035 ren & & \\
\hline ICE engine $(\$ / L)$ & 755.00 & 755.00 & & \\
\hline LiON battery $(\$ / k W h) *$ & 2000.00 & 1050.00 & & \\
\hline NiMH battery $(\$ / k W h)^{*}$ & 1384.00 & 400.00 & & \\
\hline Fuel cell cost $(\$ / \mathrm{kW})$ & 108.00 & 52.00 & & \\
\hline \multirow[t]{2}{*}{ Well-to-tank Emissions } & US $2010 \mathrm{v}$ & & US 2035 ren & \\
\hline & Hydrogen & Electricity & Hydrogen & Electricity \\
\hline VOC $(g / k g)$ & 1.40 & 0.06 & 0 & 0 \\
\hline $\mathrm{CO}(\mathrm{g} / \mathrm{kg})$ & 3.33 & 0.19 & 0 & 0 \\
\hline NOx $(g / k g)$ & 8.16 & 0.77 & 0 & 0.01 \\
\hline PM10 (g/kg) & 4.32 & 0.98 & 0 & 0 \\
\hline PM2.5 $(\mathrm{g} / \mathrm{kg})$ & 2.20 & 0.26 & 0 & 0 \\
\hline $\mathrm{CH} 4(\mathrm{~g} / \mathrm{kg})$ & 40.95 & 0.98 & 2.4 & 0.01 \\
\hline $\mathrm{N} 2 \mathrm{O}(\mathrm{g} / \mathrm{kg})$ & 0.06 & 0.01 & 0 & 0 \\
\hline $\mathrm{CO} 2(\mathrm{~g} / \mathrm{kg}) /(\mathrm{g} / \mathrm{kWh})$ & 12456.55 & 727.02 & 1020 & 3.60 \\
\hline Fuel Cost Assumptions & US $2010 \mathrm{v}$ & US 2035 ren & & \\
\hline Gasoline $(\$ / L) /(€ / L)$ & 0.52 & 1.15 & & \\
\hline Ethanol (E-85) $(\$ / L) /(€ / L)$ & 0.54 & 1.20 & & \\
\hline Diesel $(\$ / L) /(€ / L)$ & 0.41 & 0.91 & & \\
\hline Bio-Diesel $(\$ / L) /(€ / L)$ & 0.16 & 0.34 & & \\
\hline C. Natural Gas $(\$ / \mathrm{L}) /(€ / \mathrm{kg})$ & 0.79 & 1.77 & & \\
\hline Hydrogen $(\$ / \mathrm{L}) /(€ / \mathrm{kg})$ & 0.40 & 0.90 & & \\
\hline Electricity (\$/kWh) & 0.09 & 0.15 & & \\
\hline
\end{tabular}

* Note: costs are scaled by W/Wh. These values are for high-power packs 


\title{
Appendix C: Summary of Vehicle Performance Characteristics
}

\author{
$=$ Best in Class \\ $=$ Worst in Class
}

\section{US compact (1.1-1.9L) steel passenger vehicles}

\begin{tabular}{|c|c|c|c|c|c|c|c|c|c|c|}
\hline $\begin{array}{r}\text { Hybridization: } \\
\text { Chemical Energy Converter: }\end{array}$ & $\begin{array}{l}\text { None } \\
\text { Otto }\end{array}$ & $\begin{array}{l}\text { None } \\
\text { Diesel }\end{array}$ & $\begin{array}{l}\text { Mild } \\
\text { Otto }\end{array}$ & $\begin{array}{c}\text { Mild } \\
\text { Diesel }\end{array}$ & $\begin{array}{c}\text { Series } \\
\text { Otto }\end{array}$ & $\begin{array}{l}\text { Series } \\
\text { Diesel }\end{array}$ & $\begin{array}{c}\text { Series } \\
\text { Fuel Cell }\end{array}$ & $\begin{array}{c}\text { Parallel } \\
\text { Otto }\end{array}$ & $\begin{array}{c}\text { Parallel } \\
\text { Diesel }\end{array}$ & $\begin{array}{l}\text { EV } \\
\text { EV }\end{array}$ \\
\hline Weight (kg) & 1124 & 1147 & 1157 & 1179 & 1608 & 1644 & 1977 & 1622 & 1671 & 1929 \\
\hline Total power $(\mathrm{kW})$ & 99 & 89 & 102 & 92 & 157 & 157 & 100 & 168 & 178 & 140 \\
\hline \multicolumn{11}{|l|}{ Cost } \\
\hline Purchase (2010 USD) & 17468 & 19516 & 18686 & 20742 & 37251 & 39557 & $48+79$ & 36482 & 39019 & +5432 \\
\hline Operating/Maintenance (2010 USD) & 1529 & 1379 & 1484 & 1350 & 1454 & 1426 & 1306 & 1601 & 1542 & 1436 \\
\hline Total cost of ownership (2010 USD) & 28489 & 29460 & 29441 & 30535 & 48048 & 50139 & 58249 & 48231 & 50297 & 56171 \\
\hline \multicolumn{11}{|l|}{ Performance } \\
\hline 0-100 Acceleration time (s) & 8.8 & 10.0 & 8.8 & 9.9 & 7.9 & 8.1 & 15.3 & 7.5 & 7.4 & 10.7 \\
\hline 80-120 Acceleration time (s) & 3.5 & 4.0 & 3.5 & 4.0 & 3.1 & 3.2 & 6.1 & 3.0 & 2.9 & 4.2 \\
\hline Top Speed (kph) & 218 & 210 & 221 & 213 & 255 & 255 & 219 & 260 & 265 & 245 \\
\hline \multicolumn{11}{|l|}{ Utility } \\
\hline Range (km) & 705 & 956 & 767 & 1037 & 1357 & 1595 & 545 & 939 & 1180 & 327 \\
\hline All-electric range (km) & $\mathbf{0}$ & 0 & $\mathbf{0}$ & 0 & 125 & 124 & 122 & 40 & 55 & 327 \\
\hline Passenger volume $\left(\mathrm{m}^{\wedge} 3\right)$ & 2.61 & 2.61 & 2.61 & 2.61 & 2.56 & 2.56 & 2.35 & 2.56 & 2.56 & 2.39 \\
\hline Towing capacity (kg) & 1511 & 1211 & 1558 & 1258 & 2580 & 2544 & 685 & 2844 & 3072 & 1798 \\
\hline \multicolumn{11}{|l|}{ Environment } \\
\hline Gasoline Equivalent cons. (L/100km) & 8.5 & 7.2 & 7.8 & 6.6 & 4.9 & 4.7 & 3.7 & 6.7 & 6.3 & 2.2 \\
\hline Life cycle $\mathrm{CO} 2(\mathrm{~g} / \mathrm{km})$ & 259 & 216 & 240 & 202 & 184 & 176 & 174 & 236 & 220 & 215 \\
\hline Life cycle NOx (g/km) & 0.18 & 0.15 & 0.17 & 0.14 & 0.16 & 0.15 & 0.13 & 0.19 & 0.17 & 0.23 \\
\hline Life cycle PM10 $(\mathrm{g} / \mathrm{km})$ & 0.14 & 0.07 & 0.13 & 0.06 & 0.11 & 0.05 & 0.02 & 0.12 & 0.06 & 0.02 \\
\hline
\end{tabular}

\section{5 (renewable fuel) US compact (1.1-1.9L) steel vehicles}

\begin{tabular}{|c|c|c|c|c|c|c|c|c|c|c|}
\hline $\begin{array}{r}\text { Hybridization: } \\
\text { Chemical Energy Converter: }\end{array}$ & $\begin{array}{l}\text { None } \\
\text { Otto }\end{array}$ & $\begin{array}{l}\text { None } \\
\text { Diesel }\end{array}$ & $\begin{array}{l}\text { Mild } \\
\text { Otto }\end{array}$ & $\begin{array}{c}\text { Mild } \\
\text { Diesel }\end{array}$ & $\begin{array}{l}\text { Series } \\
\text { Otto }\end{array}$ & $\begin{array}{l}\text { Series } \\
\text { Diesel }\end{array}$ & $\begin{array}{c}\text { Series } \\
\text { Fuel Cell }\end{array}$ & $\begin{array}{c}\text { Parallel } \\
\text { Otto }\end{array}$ & $\begin{array}{c}\text { Parallel } \\
\text { Diesel }\end{array}$ & $\begin{array}{l}\text { EV } \\
\text { EV }\end{array}$ \\
\hline Weight (kg) & 1124 & 1147 & 1157 & 1179 & 1608 & 1644 & 1977 & 1622 & 1671 & 1929 \\
\hline $\begin{array}{l}\text { Total power }(\mathrm{kW}) \\
\text { Cost }\end{array}$ & \multicolumn{10}{|c|}{ Cost } \\
\hline Purchase (2006 USD) & 17614 & 19546 & 18281 & 20226 & 22268 & 24525 & 26547 & 21531 & 23955 & 21322 \\
\hline Operating/Maintenance (2010 USD) & 2794 & 2345 & 2638 & 2234 & 1994 & 1872 & 1285 & 2411 & 2202 & 1432 \\
\hline Total cost of ownership (2010 USD) & 43298 & 41180 & 42570 & 40869 & 40793 & 41943 & 38614 & 43787 & 44324 & 34770 \\
\hline \multicolumn{11}{|l|}{ Performance } \\
\hline 0-100 Acceleration time (s) & 8.8 & 10.0 & 8.8 & 9.9 & 7.9 & 8.1 & 15.3 & 7.5 & 7.4 & 10.7 \\
\hline 80-120 Acceleration time (s) & 3.5 & 4.0 & 3.5 & 4.0 & 3.1 & 3.2 & 6.1 & 3.0 & 2.9 & 4.2 \\
\hline Top Speed (kph) & 218 & 210 & 221 & 213 & 255 & 255 & 219 & 260 & 265 & 245 \\
\hline \multicolumn{11}{|l|}{ Utility } \\
\hline Range (km) & 705 & 956 & 767 & 1037 & 1357 & 1595 & 545 & 939 & 1180 & 327 \\
\hline All-electric range $(\mathbf{k m})$ & 0 & 0 & 0 & 0 & 125 & 124 & 122 & 40 & 55 & 327 \\
\hline Passenger volume $\left(\mathrm{m}^{\wedge} 3\right)$ & 2.61 & 2.61 & 2.61 & 2.61 & 2.56 & 2.56 & 2.35 & 2.56 & 2.56 & 2.39 \\
\hline $\begin{array}{l}\text { Towing capacity (kg) } \\
\text { Environment }\end{array}$ & 1511 & 1211 & 1558 & 1258 & 2580 & 2544 & 685 & 2844 & 3072 & 1798 \\
\hline Gasoline Equivalent cons. (L/100km) & 8.5 & 7.2 & 7.8 & 6.6 & 4.9 & 4.7 & 3.7 & 6.7 & 6.3 & 2.2 \\
\hline Life cycle $\mathrm{CO} 2(\mathrm{~g} / \mathrm{km})$ & 260 & 220 & 242 & 206 & 185 & 178 & 41 & 238 & 224 & 74 \\
\hline Life cycle NOx (g/km) & 0.13 & 0.10 & 0.12 & 0.10 & 0.12 & 0.11 & 0.05 & 0.14 & 0.13 & 0.08 \\
\hline Life cycle PM10 (g/km) & 0.09 & 0.03 & 0.08 & 0.03 & 0.06 & 0.02 & 0.00 & 0.07 & 0.03 & 0.01 \\
\hline
\end{tabular}


Appendix D: Aggregated Survey 1 Responses, unscaled (0-5 selections for criteria questions). Un-shaded criteria are used in MCDA.

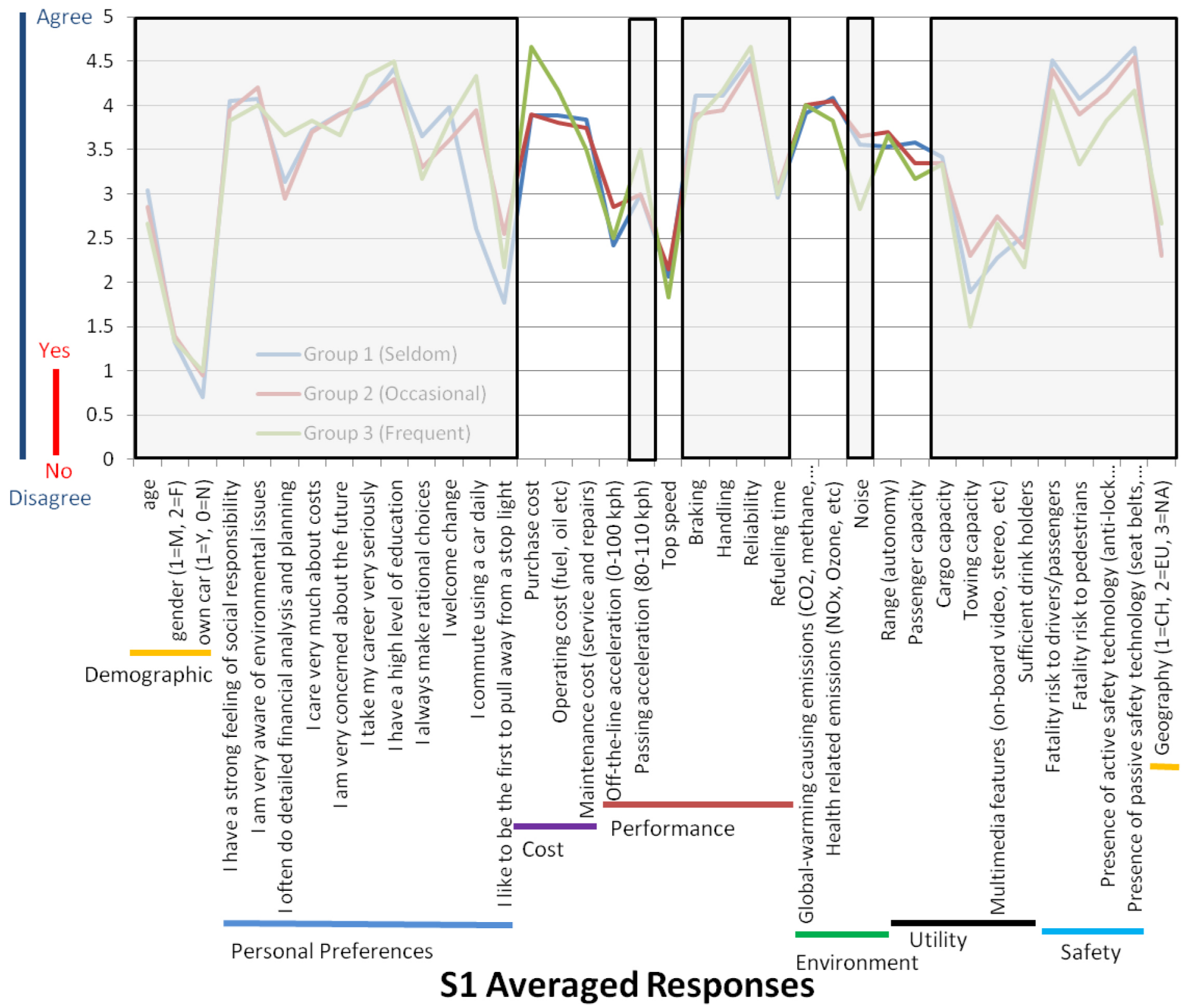


The Engineering Meetings Board has approved this paper for publication. It has successfully completed SAE's peer review process under the supervision of the session organizer. This process requires a minimum of three (3) reviews by industry experts.

All rights reserved. No part of this publication may be reproduced, stored in a retrieval system, or transmitted, in any form or by any means, electronic, mechanical, photocopying, recording, or otherwise, without the prior written permission of SAE.

ISSN 0148-7191
Positions and opinions advanced in this paper are those of the author(s) and not necessarily those of SAE. The author is solely responsible for the content of the paper.

SAE Customer Service:

Tel: 877-606-7323 (inside USA and Canada)

Tel: 724-776-4970 (outside USA)

Fax: 724-776-0790

Email: CustomerService@sae.org

SAE Web Address: http://www.sae.org

Printed in USA 